\title{
ИСКУССТВОВЕДЕНИЕ
}

\author{
УПАКОВОЧНЫЙ СТИЛЬ \\ DOI: $10.31618 / \mathrm{ESU} .2413-9335.2019 .8 .68 .467$ \\ Дюков Илья Вячеславович \\ Доцент кафедры академического рисунка \\ Российской академии живописи ваяния и зодчества Ильи Глазунова
}

\section{PACKING STYLE}

\section{АННОТАЦИЯ}

Преобладающий вид искусства в наши дни - дизайн. Через дизайнерскую призму теперь смотрят не только на тарелки и унитазы, но и на живопись, скульптуру и, конечно - архитектуру. Архитекторы превратились в разработчиков дизайнерских упаковок, предназначенных к продаже пространств.

\section{ABSTRACT}

Overwhelming with its popularity art style now days - design. Through the design point of view everybody looks not only on the toilets and plats, but on the painting, sculpture and of course architecture. Architectures turned into slaves of the design packages, which meant only for selling design spaces.

Ключевые слова: современная архитектура, упаковочный стиль, культура, дизайн

Keywords: Contemporary art, packing style, culture, dising

\section{УПАКОВОЧНЫЙ СТИЛЬ PACKING STYLE}

Всякий предмет и всякое явление сопутствующее человеку облекается им в словесную форму, именно с момента наименования начинается познание мира. Через выявление конкретных явлений в понятии начинается наука. В докладе предлагается новый термин к обозначению явления, которое ныне захватило пространства почти всех городов планеты - Упаковочный стиль (Packing style).

Эпоха, в которую мы живем равно, как и любая другая объективируется в формах искусства. Преобладающий вид искусства в наши дни дизайн. Он окутал весь предметный мир - от спичек до грандиозных по своим размерам сооружений. Во времена рыночных отношений именно дизайн стал важнейшим видом искусства. Собственно рынок и является его родителем. Сегодня остальные виды искусства вынуждены считаться с дизайном. Через дизайнерскую призму смотрят не только на тарелки и унитазы, но и на живопись, скульптуру и, конечно же, архитектуру. Теперь картина является «дизайнерским» цветовым пятном, скульптура и архитектура «дизайнерскими» арт-объектами. Особенно заметно влияние «художественного конструирования» в современной архитектуре, в которой явно произошла подмена, собственно архитектуры, принципами дизайнерских решений. Архитекторы превратились в разработчиков упаковок пространств, предназначенных для продажи. Современные города наполняются огромными незатейливыми, затейливыми и очень затейливыми коробками, в которых упакованы торговые центры, гостиницы, офисы, квартиры и все что угодно.

Город, всегда формировавшийся архитектурой, ныне формируется упаковками. В отличие от древних и старинных городов (где образ города ассоциировали с храмом, монастырем, дворцом) современный город ассоциируется с торгово-развлекательным центром. Сегодня домаупаковки, находящиеся вблизи старинных сооружений, уподобляются коробкам, обернутым цветной бумагой, стоящим рядом с антикварными произведениями. Древние строения даже в виде руин взывают к возвышенным чувствам, настраивая на созерцательный лад. Зато товарный вид нынешних домов в форме коробок и тубусов можно испортить одной царапиной, да что уж там царапиной, достаточно просто вовремя не смахнуть пыль. Современный дизайн строений, как любая упаковка, совершенно не выдерживает проверки временем. В древности обществами с религиозным мировоззрением пространство понималось сакрально, что и находило отражение в форме и образе города. Классические (греческий, византийский и древнерусский) города гармонично вписывались в природное пространство. Их создатели стремились избегать «конфликтов» с окружающей средой. Однако уже римские градостроители расценивали окружающее пространство иначе: человек есть хозяин. Антропоцентризм - вот причина подобного отношения.

Современная ситуация в комбинации человек - город - окружающее пространство во многом напоминает римскую ситуацию: тот же антропоцентризм с внешней римской религиозностью (большинство людей и сегодня, согласно статистике, относят себя к той или иной конфессии). Сейчас, как и в римскую эпоху, центром города является не храм и даже не замок или дворец, а место для торговли и развлечений торгово-развлекательный центр. «Хлеба и зрелищ» - вот девиз современного общества, которое подобно римскому плебсу с наслаждением взирает на кровавые сцены смерти, правда, не в Колизее, хрустя морковкой, а в кинозале, хрустя попкорном и запивая его Кока-колой. Впрочем, между римским обществом и современным есть существенное различие. Римлянин стремился все 
подчинить интересам божественного Города: соседние народы с их культурами, природу и даже богов - в этом и было ядро его антропоцентризма. Современный человек шагнул дальше, он преодолел эту форму мировоззрения и стал утверждать новую. Выгода - вот тот вирус, который засел в головах людей нашего века. Выгодно каждый год делать ремонт, менять дорожное покрытие, перестраивать дома. Выгодно на двадцати квадратных метрах строить сто этажей.

Архитекторы-дизайнеры мотивируют посвоему. У профессионалов, ныне ходячее сравнение архитектуры с пошивом одежды. «Не будешь же всю жизнь носить одно пальто»- говорят они. Таким образом, зданию отмеряется век чуть больше, чем пальто или штанам. Да и как может быть иначе, когда сами архитекторы все чаще отказывают архитектуре вправе называться искусством. Теперь она - упаковка.

Упаковка, может иметь какую угодно форму, главное, чтобы она привлекала к себе всеобщее внимание. Пространства, выставленные на продажу под офисы, рестораны, ледовые центры и т. п., должны быть упакованы в дешевый, легкий, а главное, привлекательный материал. Материал этот своей раскраской может, напоминать обувную коробку или обертку от конфет, он может имитировать корабль или льдину, кристалл или памятники архитектуры прошлых столетий. Все что угодно, лишь бы продавалось. Имитация, эрзац, псевдоморфоз, симулякр стали главными атрибутами всей современной культуры. Однако в строительстве имитация проявилась особенно наглядно. Потребитель знает что «сталинки» построены хорошо. Для торговца пространством это означает, что их надо сымитировать, для чего необходимо архитектору и строителям сформулировать техническое задание - чтобы как при Вожде, только в десять раз дешевле и площадей в десять раз больше. Так в Москве возникают дешёвые (в производстве) элитные жилища, наивно имитирующие сталинскую архитектуру.

Упаковывать - пространства, события, новости и вообще все что угодно - придумали на Западе, где прибыль стала альфой и омегой.
Теоретики и практики модернистской и постмодернистской архитектуры, возможно, и не сознавали того, что их деятельность, в конечном счете, нацелена на создание хорошей упаковки. Однако их заказчики отдавали себе в этом отчет. Западные строения упакованы хорошо и с сознанием дела. А вот советские сооружения $60-$ 80-х гг. упакованы не так хорошо - топорно, тяжеловесно. Наши архитекторы никак не могли понять того факта, что современная им архитектура Запада, на которую они ориентировались, переставала быть архитектурой, она превращалась в дизайн упакованных пространств, выставленных на продажу. Советские архитекторы продолжали осваивать методы проектирования классического наследия, но при этом с широко раскрытыми глазами смотрели в рот западным коллегам. Заказчик же в лице государства, начиная с конца 50-х, хотел простых и дешёвых решений. Творения отечественных архитекторов 40-50 гг. и постройки 60-70x. тех же авторов представляют собой нечто совершенно непохожее. Дело в том, что в марте 1953г. умер главный заказчик - Сталин, вот и все.

Нынешние отечественные архитекторы продолжают уступать заграничным коллегам, ведь они все еще никак не освоятся с новой профессией - упаковщиков. Мир объемных форм, который окружает современного горожанина, отныне формируется не архитекторами, а дизайнерами упаковки. Впрочем, конец упаковки известен после использования ее без сожаления выбрасывают как ненужный хлам.

Упаковочный стиль (Packing style) в градостроительстве представляет собой явление характерное для формирования городских пространств в XX-ХХІвв. Его отличительные черты - безыдейность (если не считать обслуживания интересов бизнеса), эклектизм, часто лаконизм, функциональный утилитаризм, экстравагантная отделка сооружений, использование новых технологий. $\mathrm{He}$ редко «Упаковочный стиль» агрессивен в отношении сложившихся архитектурных ансамблей и памятников прошедших эпох. Его эстетическая основа - дизайн. 